\title{
Doxylamine succinate overdose: Slurred speech and visual hallucination
}

\author{
Okşan Derinöz-Güleryüz \\ Department of Pediatric Emergency, Gazi University Faculty of Medicine, Ankara, Turkey. \\ E-mail: oksan197@yahoo.com or oderinoz@gazi.edu.tr \\ Received: 7th June 2017, Revised: 30th July 2017, Accepted: 30th August 2017
}

SUMMARY: Derinöz-Güleryüz O. Doxylamine succinate overdose: Slurred speech and visual hallucination. Turk J Pediatr 2018; 60: 439-442.

Doxylamine succinate is a commonly used antihistamine for respiratory allergies including allergic rhinitis as well as for the management of insomnia. As it is available over-the-counter like other nonprescription antihistamines and sleep aids, there is a risk of overdose. It is believed that doxylamine succinate has both peripheral and central activity with its anticholinergic properties. Delirium, seizures, and coma are among the central adverse effects that are rare. This case was presented since it is the first case in the literature who developed slurred speech and visual hallucination after high dose doxylamine succinate use and received antidotal therapy for anticholinergic side effects.

Key words: doxylamine, overdose, slurred speech, visual hallucination.

Doxylamine succinate (DS) is a first-generation antihistamine that is used in the treatment of allergic rhinitis or other respiratory allergies in combination with other drugs in children between 2 to 6 years, and in the treatment of insomnia due to its sedative effects in children older than 12 years and in adults. ${ }^{1,2}$ The use of antihistamines steadily increases and they are the $9^{\text {th }}$ drug on the frequency list of human exposure to substances. ${ }^{3}$ Doxylamine succinate overdose causes both peripheral (fever, warm and dry skin, mydriasis, hypoactive bowel sounds, skin flushing, bladder retention, and tachycardia) and central (delirium, seizures, and coma) side effects with its anticholinergic properties. ${ }^{1,4}$

Doxylamine succinate poisoning is very rare. In a study that evaluated 6570 autopsies performed between 1987 and 1997, DS was detected in the blood and tissues of 13 cases only. While other substances such as alcohol, cocaine, morphine were also detected together with DS in 11 of these cases, DS was detected alone in only 2 cases. ${ }^{5}$

In the literature, there are cases who developed rhabdomyolysis. ${ }^{6,7}$ Rhabdomyolysis related acute renal failure, pancreatitis ${ }^{8}$, and inappropriate antidiuretic hormone syndrome ${ }^{9}$ after DS overdose have been reported.

Here, poisoning symptoms of DS overdose are discussed. The most important distinctive feature of this case is the development of rare side effects such as slurred speech and visual hallucination following DS overdose. Another important feature of our case is the reversal of these clinical signs with antidotal therapy. To our knowledge, antidote administration has not been reported due to DS toxicity.

\section{Case Report}

A previously healthy 15-year-old girl was brought to the Pediatric Emergency Department (PED) of our hospital two hours after taking 80 DS pills (25 mg per pills; total dose; 40 $\mathrm{mg} / \mathrm{kg}$ ) for suicide. Upon arrival, her physical examination revealed; general Glasgow Coma Score 15, vital signs were (temperature; 36.8 ${ }^{\circ} \mathrm{C}$, blood pressure; $100 / 60 \mathrm{mmHg}$, heart rate; 98/bpm, respiratory rate; $16 /$ minute) stable and she was conscious. She had visual hallucinations and slurred speech. There were no other peripheral and central side effects caused by

This manuscript was presented at the 13th Congress of Pediatric Emergency and Intensive Care, Izmir, Turkey. 
the DS overdose. Since the patient presented at 2 hours after ingestion gastric lavage was not performed only $1 \mathrm{~g} / \mathrm{kg}$ activated charcoal was given. Blood glucose, renal and liver function tests, blood alcohol level and b-HCG levels were normal. Toxicological screening (barbiturate, paracetamol, salicylate) was negative. ECG was normal. There were not any other abnormal findings such as QRS widening or ventricular tachycardia on her ECG. Laboratory test results of the patient are presented in Table I.

At $20^{\text {th }}$ minute of emergency department arrival, she had a generalized tonic-clonic seizure for three minutes which responded to $0.01 \mathrm{mg} /$ $\mathrm{kg}$ intravenous (IV) midazolam. Flushing, tachycardia (140 beats/minute) mydriasis developed concurrently. Hallucinations continued and her speech was gradually distorted. Since the patient developed central anticholinergic side effects (seizure, hallucination and agitation) in addition to peripheral anticholinergic side effects, physostigmine at a dose of $0.02 \mathrm{mg} / \mathrm{kg}$ (maximum $0.5 \mathrm{mg}$; at a rate no more than $0.5 \mathrm{mg} /$ minute) was given intravenously. After physostigmine, her tachycardia and flushing regressed, her speech started to improve and visual hallucinations reduced. As her complaints did not recur in the next 48 hours of observation, physostigmine treatment was not repeated.

She was also monitored for rhabdomyolysis, the most frequent side effect of DS overdose. Creatinine kinase $(C K)$ increased at the $6^{\text {th }}$ hour of admission. Therefore, alkaline diuresis with IV sodium bicarbonate ( 1 to $2 \mathrm{mEq} / \mathrm{kg}$ IV bolus starting dose, titrate to blood $\mathrm{pH} 7.45$ to 7.55) was started. CK level was monitored with urine alkalization. She was hospitalized as her DS dose was accepted as lethal $(40 \mathrm{mg} / \mathrm{kg})$ and her CK level needed to be followed. The patient whose clinic and laboratory findings improved completely was discharged almost 48 hours of admission.

Informed consent was obtained from patient's family.

\section{Discussion}

This case is the first case in the literature who developed slurred speech and visual hallucination due to DS overdose and received antidote to reverse the CNS effects caused by toxic dosages of DS.
The plasma concentration of DS, which has a half-life of 10-12 hours, peaks 2-3 hours following the oral intake at a dose of $25 \mathrm{mg}$. $2,4,5$ Hepatic metabolism is the primary route of metabolism for doxylamine succinate. It is mostly $(60 \%)$ eliminated through urinary route without being metabolized and remainder is metabolized through various metabolic parthways. ${ }^{1,2,4,11}$ A lethal dose of $25-250 \mathrm{mg} /$ $\mathrm{kg}$ body weight in humans is reported for this drug. ${ }^{12}$ As our patient took $40 \mathrm{mg} / \mathrm{kg}$ DS, her dose was accepted as lethal so she was observed until her clinic and laboratory findings were normal.

Even though the most frequent side effects of DS overdose are warm and dry skin and mydriasis, rhabdomyolysis is also commonly seen. Rhabdomyolysis is frequently seen in cases with doxylamine succinate overdose in the absence of situations that causes rhabdomyolysis such as trauma, seizure, shock or crush injury. 7,8 Its exact mechanism is not known. Rhabdomyolysis was seen in $87 \%$ of the cases after doxylamine use over $20 \mathrm{mg} / \mathrm{kg}$ and this dose is enough to cause rhabdomyolysis. ${ }^{13}$ In another study, it was reported that patients with doxylamine use higher than $13 \mathrm{mg} /$ $\mathrm{kg}$ developed rhabdomyolysis. ${ }^{8}$ Although our patient took $40 \mathrm{mg} / \mathrm{kg}$ of DS, rhabdomyolysis developed more subtly. While increased CK level was considered to be related to druginduced rhabdomyolysis, it is also possible that short-term generalized seizure in our case might have increased CK level.

In a study which investigated 140 cases younger than 5 years with accidental doxylamine intake, it was reported that severe poisoning symptoms do not develop after accidental doxylamine intake and temporary apathy and tachycardia occur with drug intake over $6.2 \mathrm{mg} / \mathrm{kg} .{ }^{14}$

In another study which evaluated 109 cases with doxylamine poisoning, it was found that drug intake was 10 to 40 times that of the therapeutic dose in $60 \%$ of the cases and no symptoms developed in $39 \%$ of the cases. ${ }^{11}$ In patients with clinical symptoms, tachycardia, 'psychosis' similar to catatonic stupor, changes in consciousness, and seizure were seen most frequently seen. The most serious complications were rhabdomyolysis and renal dysfunction related to this, and acute renal failure. For detoxification, gastric lavage, active charcoal, 
Table I. Laboratory Values at Admission and During Observation Period.

\begin{tabular}{lcccc}
\hline & At admission & At $6^{\text {th }}$ hour & At $18^{\text {th }}$ hour & At $30^{\text {th }}$ hour \\
\hline BUN (mg/dl) & 8 & 7 & 7 & 6 \\
Creatinine (mg/dl) & 0.88 & 0.89 & 0.87 & 0.84 \\
Creatinine Kinase (U/L) & 100 & 365 & 438 & 385 \\
Uric Acid (mg/dl) & 6.7 & 8.8 & 7.2 & 5.7 \\
Myoglobin (ng/ml) & $<21$ & 105.5 & 34.83 & - \\
Amylase (U/L) & 50 & - & - & - \\
\hline
\end{tabular}

BUN reference range: $5-18 \mathrm{mg} / \mathrm{dl}$; Creatinine reference range: $0.57-0.87 \mathrm{mg} / \mathrm{dl}$; Creatinine kinase reference range: $0-190$ U/L; Uric Acid reference range: 2.2-6.4 mg/dl; Myoglobin reference range: 25-58 ng/ml; Amylase reference range: $28-$ $100 \mathrm{U} / \mathrm{L}$

and sodium sulfate have been used. Antidotal therapy was not recommended in any case. Although some studies suggest the significance of blood doxylamine level, this study did not find a correlation between blood doxylamine levels and clinical findings and indicated nonsignificance of blood doxylamine levels. ${ }^{11}$

In most cases, the treatment of doxylamine succinate overdose includes supportive care and symptomatic treatments such as gastric lavage, active charcoal, monitoring for vital signs, and cardiac monitoring. However, antidotal therapy including physostigmine may be required in severe cases. ${ }^{15}$ The indications for physostigmine use in doxylamine succinate poisoning is the emergence of peripheral and central anticholinergic symptoms (moderate to severe agitation/delirium). Pediatric dose of physostigmine is $0.02 \mathrm{mg} / \mathrm{kg}$ (IV). Its maximum dose in children is $0.5 \mathrm{mg}$, IV infused over at least 5 minutes. Rapid administration may cause bradycardia, hypersalivation leading to respiratory difficulty, and possibly seizures. ${ }^{1}$ Although physostigmine has a relatively shorter half-life (15 minutes), its effects may continue longer than expected. In patients with recurring psychotic symptoms, supplementary doses can be given in small portions after 20-30 minutes. In our case, antidotal therapy was started due to the emergence of drug related peripheral and central anticholinergic symptoms. Antidotal therapy successfully regressed both peripheral and central symptoms related to doxylamine succinate overdose.

Since antihistamines are nonprescription medication and easy to find, they are frequently used in suicide attempts. It should be kept in mind that DS overdose may develop symptoms (i.e. visual hallucinations, slurred speech) other than those frequently reported. Treatment in most cases includes supportive care and symptomatic treatments (gastric lavage, active charcoal, vital sign monitoring, and cardiac monitoring) and patients frequently are discharged without a sequel. However, severe clinical signs may emerge in some patients and antidote may be added to the management plan.

\section{REFERENCES}

1. Weisman RS. Chapter 50: Antihistamines and Decongestants. In: Hoffman, Nelson, Lewin, Flomenbaum, Goldfrank eds, Goldfrank's Manual of Toxicologic Emergencies, USA, McGraw-Hill Education; 2007: 434-440.

2. htt p://www.uptodate.com/contents / doxylamine-druginformation? source $=$ search result \& se a r ch $=$ d ox y la min ed rug\% $2 \overline{0}$ information\&selectedTitle $=1 \sim 40$ (Accessed: January 29, 2017).

3. Bronstein AC, Spyker DA, Cantilena LR Jr, Green JL, Rumack BH, Dart RC. 2010 Annual Report of the American Association of Poison Control Centers' National Poison Data System (NPDS): 28th Annual Report. Clinical Toxicology 2010; 49: 910-941.

4. Manning B. Antihistamines. In: Olson KR. Poisoning and Drug Overdose. (6th ed). USA, McGraw-Hill Education; 2012: 104-106.

5. Anderson IB, Doss C. Table: Pharmacokinetic Data. In: Olson K.R. Poisoning and Drug Overdose. (6th ed). USA, McGraw-Hill Education; 2012: 412-437.

6. Bockholdt B, Klug E, Schneider V. Suicide though doxylamine poisoning. Forensic Sci Int 2001; 119: 138-140.

7. Khosla U, Ruel KS, Hunt DP. Antihistamine-induced rhabdomyolysis. South Med J 2003; 96: 1023-1026.

8. Kim HJ, Oh SH, Youn CS, et al. The associative factors of delayed-onset rhabdomyolysis in patients with doxylamine overdose. Am J Emerg Med 2011; 29: 903-907. 
9. Lee YD, Lee ST. Acute pancreatitis and acute renal failure complicating doxylamine succinate intoxication. Vet Hum Toxicol 2002; 44: 165-166.

10. Carrascosa MF, Caviedes JR, Lucena MI, CuadradoLavín A. Syndrome of inappropriate antidiuresis in doxylamine overdose. BMJ Case Rep2012; 19: 1-3.

11. Köppel C, Tenczer J, Ibe K. Poisoning with over-thecounter doxylamine preparations: an evaluation of 109 cases. Hum Toxicol 1987; 6: 355-359.
12. Müller RK. Toxicological Analysis. Ullstein-Berlin Mosby, 1992.

13. Jo YI, Song JO, Park JH, et al. Risk factors for rhabdomyolysis following doxylamine overdose. Hum Exp Toxicol 2007; 26: 617-621.

14. Cantrell FL, Clark AK, McKinley M, Qozi M. Retrospective review of unintentional pediatric ingestions of doxylamine. Clin Toxicol (Phila) 2015; 53: $178-180$

15. Beaver KM, Gavin TJ. Treatment of acute anticholinergic poisoning with physostigmine. Am J Emerg Med 1998; 16: 505-507. 